The BDJ News section accepts items that include general news, latest research and diary events that interest our readers. Press releases or articles may be edited, and should include a colour photograph if possible.

Please direct your correspondence to the News Editor, Kate Maynard at the BDJ, The Macmillan Building, 4 Crinan Street, London N1 9XW or by email to

k.maynard@nature.com

\section{RESOURCE LAUNCHED TO SUPPORT EEA QUALIFIED PRACTITIONERS}

A new resource has been developed to help support non-UK, European Economic Area (EEA) qualified dental practitioners practising in the UK. It has been designed to provide an overview of the 19 EEA member states, which have supplied 97\% of the EEA dentists currently registered by the General Dental Council (GDC), to improve knowledge and understanding of the professional background of dentists who have obtained their primary dental qualification from a non-UK, EEA member state.

On 31 December 2010, of the 38,377 dentists registered with the GDC, some 10,768 had qualified outside the UK. Of these, more than 6,300 were EEA dentists with non-UK qualifications.
The primary aim of the new resource is to provide information for primary care organisations, deaneries and other organisations about the regulatory mechanisms, education and training, support systems, dental team and skill mix, delivery of oral healthcare, quality assurance mechanisms and culture within the 19 EEA member states.

The resource is available at: www.oxforddeanery.nhs.uk/ dental_school/eea_dentists_ information.aspx.

\title{
NO SMOKING DAY A SUCCESS FOR THE DDS
}

Over 100 Army, Royal Navy and Royal Air Force dental centres from the Defence Dental Services (DDS) participated in events for No Smoking Day (NSD) 2011 across the UK and as far afield as Germany and Cyprus.

DDS clinicians are in a unique position to positively influence

\section{smoking behaviour as each}

Serviceperson is required

to have a Periodic Dental

Inspection. This provides

the chance for an intervention and appropriate referral to a smoking cessation clinic.

Military participation in NSD

enabled Defence healthcare professionals a coordinated effort to raise awareness of the dangers of smoking and the potential benefits of quitting. In preparation for the event each dental centre received an official NSD pack containing leaflets, balloons, posters, pens and branded t-shirts. Additional health promotion resources could be ordered on request or accessed online. Many dental centres produced their own materials for the event, including one team who constructed a giant 5 foot long cigarette as part of their display.

With a patient base of almost 200,000 Servicemen and women and a current smoking incidence of $28 \%$, reducing the level of smoking in the military population is a priority. A high tempo, high pressure cycle of training, deploying and recovering from overseas operations, means smoking is common and habits are especially difficult to break.

'For the DDS, NSD is a successful oral health promotion event that raises awareness across thousands of patients,' said Squadron Leader Mark Dermont. 'It is an event that can influence existing smokers and also new recruits at vital life transition points who are yet to take up smoking.'
GENE LINKS SKULL AND TEETH ABNORMALITIES

Researchers at the University of Helsinki have described a new, recessively inherited human syndrome featuring craniosynostosis, maxillary hyperplasia, delayed tooth eruption and extra teeth. ${ }^{1}$

In craniosynostosis, the sutures between skull bones become ossified prematurely, affecting skull shape and limiting space for the growth of the brain. It is observed in 1:25,000 births and often requires operative surgery. Supernumerary teeth are more common, and in most cases they also require dental surgery.

A combination of these anomalies was observed in four children of a Pakistani family living in Denmark. Extra teeth developed in positions suggesting that they may represent a third set of teeth.

The parents of the family were first cousins, which made it possible to localise the gene in the genome and identify the mutation, causing a change of a single amino acid, in a gene for interleukin 11 receptor alpha (IL11RA). This is a protein on cell surface that binds the extracellular interleukin 11 and makes possible for the cells to sense the presence of this factor.

'In the future it may be possible to use modulation of IL11 signaling for treatment of craniosynostosis,' said Dr Pekka Nieminen, the leader of the study.

1. Nieminen $P$, Morgan N V, Fenwick A L et al. Inactivation of IL11 signaling causes craniosynostosis, delayed tooth eruption, and supernumerary teeth. Am J Hum Genet 2011; 89: 67-81. 